\title{
Formas de interacción entre jóvenes de origen étnico en Monterrey con relatos audiovisuales extranjeros de ficción mediados por los medios de comunicación
}

\section{Oscar Mario Miranda-Villanueva ${ }^{1}$}

Recibido: 2015-05-19

Enviado a pares: $2015-05-19$
Aprobado por pares: 2015-06-09

Aceptado: 2015-06-21

DOI: 10.5294/pacla.2016.19.1.9

Para citar este artículo / To reference this article / Para citar este artigo Miranda-Villanueva, 0. M. (Marzo de 2016). Formas de interacción entre jóvenes de origen étnico en Monterrey con relatos audiovisuales extranjeros de ficción mediados por los medios de comunicación. Palabra Clave, 19(1), 211-239. DOI: 10.5294/pacla.2016.19.1.9

\section{Resumen}

La pregunta que origina este artículo responde a la manera en que se da la interacción entre jóvenes pertenecientes a grupos étnicos y que migraron a Monterrey y a algunos relatos audiovisuales extranjeros de ficción que consumen. Los resultados del análisis discursivo de entrevistas narrativas se utilizan para discutir las teorías del neoinstitucionalismo y el marco de la domesticación. El argumento es que si bien parece haber una cultura del mundo emergente por el origen del contenido de los medios audiovisuales que consumen los jóvenes de origen étnico, el análisis discursivo de la manera en que consumen dicho contenido sugiere más una diversidad cultural latente.

1 Tecnológico de Monterrey, México. oscar.miranda@itesm.mx 


\section{Palabras clave}

Cultura del mundo, diversidad cultural, domesticación, neoinstitucionalismo, relatos audiovisuales (Fuente: Tesauro de la Unesco).

\section{Forms of Interaction between Young People of Ethnic Origin in Monterrey with Foreign Audiovisual Fiction Stories of Mid Media}

\section{Abstract}

The question that brought about this article, answers how the interaction between young people belonging to ethnic groups that migrated to Monterrey and some foreign audiovisual fiction stories that they consume. The results of discourse analysis of narrative interviews are used to discuss the theories of institutionalism and under domestication. The argument is that while it seems to be an emerging world culture through the origin of the audiovisual media content consumed by young people of ethnic origin, discursive analysis of how they consume the content suggests more of a latent cultural diversity.

\section{Keywords}

World culture, cultural diversity, domestication, neo-institutionalism, audiovisual stories (Source: Unesco Thesaurus). 


\section{Formas de interação entre jovens de origem étnica em Monterrey com relatos audiovisuais estrangeiros de ficção mediados pelos meios de comunicação}

\section{Resumo}

A pergunta que origina este artigo se refere a como se dá a interação entre jovens pertencentes a grupos étnicos e que migraram a Monterrey e a alguns relatos audiovisuais estrangeiros de fição que consomem. Os resultados da análise discursiva de entrevistas narrativas são utilizados para discutir as teorias do neoinstitucionalismo e o âmbito da domesticação. $\mathrm{O}$ argumento está em que, embora pareça haver uma cultura do mundo emergente pela origem do conteúdo dos meios audiovisuais que os jovens de origem étnica consomem, a análise discursiva da maneira em que consomem esse conteúdo sugere mais uma diversidade cultural latente.

\section{Palavras-chave}

Cultura do mundo, diversidade cultural, domesticação, neoinstitucionalismo, relatos audiovisuais (Fonte: Tesauro da Unesco). 


\section{Introducción}

A partir del escrito de Morley y Silverstone (1990) y de la propuesta subsecuente de Silverstone, Hirsch y Morley (1992), la proporción de investigaciones desarrolladas en relación con el marco de la domesticación es considerable. Los trabajos empíricos que en particular se relacionan con la domesticación de relatos extranjeros sugieren que hay tres líneas de estudio para dicho fenómeno. Por un lado, se encuentra la línea de estudio que analiza la domesticación de noticias internacionales (Gurevitch, Levy y Roch, 1991; Alasuutari, Qadir y Creutz, 2013; Qadir y Alasuutari, 2013). Por otro lado, se encuentra la línea de estudio que analiza la relación entre los individuos y el texto audiovisual (Hall, 1980; Liebes, 1996; Liebes y Katz, 1990/2007; Livingstone y Lunt, 2002). Y finalmente está la línea que estudia la relación entre los individuos pertenecientes a minorías, o diásporas, y los medios y su contenido (Bailey, 2007; Bennett et al., 2006; Gumpert y Drucker, 2007; Lee y Cho, 1990; Levo-Henriksson, 2007; Robins y Aksoy, 2005; Robins y Aksoy, 2006).

El presente trabajo se sitúa en la última línea de estudio antes mencionada. La pregunta que se intenta responder se refiere a la manera en que jóvenes de origen étnico en Monterrey interactúan con relatos audiovisuales. La contribución de este artículo a la literatura existente en el tema se encuentra en la exploración de la manera en que dichos jóvenes se apropian, objetivan, incorporan o transforman algunos relatos audiovisuales extranjeros de ficción que consumen.

La apropiación se refiere al hecho de trasladar una idea de lo estrictamente público a lo privado y de expropiar un mensaje del espectro mediático de consumo y darle significación. Si bien la apropiación hace referencia explícita al tránsito de ideas, esta concepción debe complementarse o ampliarse con las líneas rutinarias de pensamiento y acción que menciona Alasuutari (2004) porque clarifican mejor el campo de acción de la apropiación por parte del individuo. La objetivación, por otro lado, está más relacionada con el espacio físico que se le atribuye al relato audiovisual. Este se refiere

2 En Monterrey hay un estimado de 11382 habitantes de 5 y más años que hablan lengua indígena, que constituyen alrededor de $1 \%$ de la población total de ese municipio para 2010. 
a la identificación con el texto audiovisual; se objetivan los valores, la estética y el universo cognitivo de los individuos.

La incorporación, a diferencia de la objetivación, se refiere a la temporalidad que se destina al texto audiovisual. Son las rutinas interiores que el individuo efectúa respecto de los contenidos mediáticos de los medios de comunicación tradicionales y las nuevas tecnologías dentro del hogar. La transformación, finalmente, tiene que ver con el hecho de trasladar el relato audiovisual de lo privado a lo público. Es el proceso mediante el cual se comparte la significación atribuida al relato audiovisual con el resto de los colegas, familiares o amigos más cercanos. Es el hecho de compartir dentro del momento que comúnmente se denomina la comidilla de la casa.

Además de estos conceptos pertenecientes al marco de la domesticación, también es importante analizar las formas de interacción antes mencionadas desde la perspectiva neoinstitucional, porque ello ayuda a entender las líneas rutinarias de pensamiento y acción que son inculcadas en dichos jóvenes con los relatos audiovisuales que consumen. El neoinstitucionalismo (Berger y Huntington, 2002; Meyer et al., 1997; Thomas, 2007) sugiere que las líneas rutinarias de pensamiento y acción se cristalizan a través de los relatos audiovisuales extranjeros de ficción, y se difunden en proporciones masivas con los distintos medios de comunicación tradicionales y las nuevas tecnologías.

Las líneas rutinarias de pensamiento y acción, desde una perspectiva neoinstitucional, funcionan como procesos de dosificación porque organizan las diferencias y las disyuntivas de los consumidores en una suerte de procedimiento de orden ontológico, donde el consumidor no tiene más remedio que reproducir las líneas rutinarias de pensamiento y acción de los relatos audiovisuales que se le colocan a su disposición. Por lo tanto, el consumidor tiende a reproducir las líneas rutinarias de pensamiento y acción de la categoría de personas que producen los relatos audiovisuales de ficción. En la mayoría de los casos, estos relatos son de procedencia extranjera y tienen sus orígenes en un pequeño grupo de países desarrollados (Antola y Rogers, 1984; Martínez, 2005; Nordenstreng y Varis, 1974). 
Aunque los jóvenes de origen étnico en Monterrey se encuentran en una condición de migración, de su lugar de origen a un área urbana, y los relatos audiovisuales a su disposición son más diversos que el rango de opciones que encuentran en su lugar de origen, el análisis de las formas de interacción entre las líneas rutinarias de pensamiento y acción de estos relatos con dichos jóvenes resulta de particular interés porque ello contribuye a la definición de una diversidad cultural o una cultura del mundo en función de lo que discuten el par de teorías arriba mencionadas.

El argumento central de este artículo apoya la idea de que, si bien parece haber una cultura del mundo emergente basada en el origen de los relatos audiovisuales consumidos por los jóvenes, el análisis de la formas de interacción sugiere algo distinto porque las referencias textuales de los informantes respecto de estos relatos vislumbra un cambio de significación y construcción de los contenidos en relación con la cultura y la ideología de los consumidores. Este estudio sugiere seis tipos de referencias según sus relatos: códigos de conducta o normas morales del hogar, perfil de uno de los actores en semejanza al perfil del consumidor, instituciones en el contexto local inmediato, situaciones de la vida cotidiana, prácticas del género femenino y comparación internacional.

En las líneas siguientes, describo la organización del artículo. En la sección del marco teórico, se discuten algunas investigaciones previas desde las perspectivas teóricas del marco de la domesticación y el neoinstitucionalismo. Las investigaciones que se discuten sirven para esclarecer la contribución de este escrito a la literatura existente en la misma área de estudio. En la sección subsecuente, se habla del tipo de datos y la metodología utilizada para su recolección y análisis. En la sección de resultados, se trata de responder al interrogante de la presente investigación. Se explicita la manera en que jóvenes de origen étnico en Monterrey interactúan con líneas rutinarias de pensamiento y acción mediadas por los medios de comunicación tradicionales y las nuevas tecnologías. Finalmente, en la sección de conclusiones, se discuten los hallazgos respecto de las perspectivas teóricas presentadas a lo largo del trabajo. 


\section{Marco teórico}

En las líneas próximas, realizo una descripción condensada de dos aproximaciones teóricas que vislumbran el proceso de consumo de los relatos audiovisuales: el marco de la domesticación y el neoinstitucionalismo. En ellas me refiero, a través de ejemplificaciones con investigaciones empíricas previas, a los mecanismos de cohesión entre una y otra perspectiva respecto del fenómeno de estudio. El marco de la domesticación entiende el consumo de relatos audiovisuales como la adecuación de líneas rutinarias de pensamiento y acción a la vida diaria de los individuos, mientras que el neoinstitucionalismo relaciona los relatos audiovisuales con la forma de instituir líneas rutinarias de pensamiento y acción en los individuos.

\section{Marco de la domesticación}

El marco de la domesticación tiene una fuente antropológica (Morley y Silverstone, 1990) y otra de consumo (Campbell, 1992). En el contexto de la interacción entre el individuo y los relatos audiovisuales, este marco sugiere cuatro momentos, arriba ya descritos, que se llevan a cabo durante el proceso de la domesticación (Silverstone, Hirsch y Morley, 1992): apropiación, objetivación, incorporación y transformación. Cada uno de ellos corresponde a un proceso distinto entre el individuo y el texto audiovisual fuera y dentro del hogar.

En el contexto de la domesticación de las noticias, existen varias aportaciones. No obstante, la mayoría se circunscribe a las perspectivas del espacio y el tiempo. Por un lado, Gurevitch, Levy y Roch (1991, p. 206) sugieren dos momentos distintos en el proceso de domesticación de lo foráneo. El primer momento se refiere a colocar hechos lejanos en moldes que sean comprensibles, atractivos y relevantes para las audiencias nacionales. Y el segundo a la construcción de significados de los hechos de manera tal que sean compatibles con la cultura y la ideología dominante de las sociedades donde se están consumiendo las noticias.

Y, por otro lado, Alasuutari, Qadir y Creutz (2013) y Qadir y Alasuutari (2013) contribuyen a la teorización de la domesticación de noticias, pero desde la perspectiva del tiempo. El argumento central de este enfoque 
está centrado en la idea de que actores políticos promueven y legitiman líneas rutinarias de pensamiento y acción a través del texto audiovisual. Estas ideas se van consolidando en la vida cotidiana de las personas, llegando eventualmente a ser domesticadas en el acontecer diario de los individuos que las consumen.

Hall (1980), Livingstone y Lunt (2002) y Liebes (1996) realizan propuestas que contribuyen al entendimiento de la interacción entre el individuo y el texto audiovisual desde la perspectiva de la objetivación. Me refiero a los planteamientos de los tipos de códigos de Stuart Hall (1980), el espectador crítico de Livingstone y Lunt (2002) y la participación del individuo en las formas de ver la televisión de Liebes (1996).

Las intenciones del conjunto de procesos que propone Hall (1980) son analizar las formas en que los mensajes transmitidos con la televisión son decodificados por el espectador. Para ello, formula tres maneras distintas de decodificar un mensaje, las cuales hacen referencia a lo siguiente: el código dominante, el código negociado y el código oposicional. Para Hall, el código dominante ocurre "cuando el espectador toma el significado connotado de, digamos, un noticiero de televisión o un programa de actualidad de forma plena y directa, y decodifica el mensaje en términos del código de referencia en el que se ha codificado" (p. 125).

El código negociado, por otro lado, es discutido en dos momentos distintos. En una primera instancia, el individuo legitima y entiende, o decodifica, lo que el mensaje contiene. Pero después ese mismo individuo es el que decide y elige modificar, o decodificar, en su favor el mensaje. Este código ofrece la posibilidad al individuo de adaptar puntos de vista distintos de su actual forma de pensar. Pero siempre dando prioridad a la decodificación del mensaje en favor de sus condiciones locales inmediatas y de su forma actual de pensar respecto de ellas. Finalmente, en el código oposicional no hay un marco de posibilidades para decodificar el mensaje de la forma como fue codificado por la fuente. El individuo decodifica siempre a su parecer el mensaje, colocándolo en una posición distinta o alternativa de la originalmente codificada. 
Otra de las aproximaciones al conjunto de procesos que organizan la diversidad cultural se refiere a la propuesta del espectador crítico de Livingstone y Lunt (2002). Para estos autores, el espectador crítico se refiere principalmente a la composición y la evolución de algunas de las características de tres distintos enfoques: la teoría literaria, el análisis cultural marxista y la teoría de los medios. Respecto de la teoría literaria, los autores le atribuyen al espectador crítico las propiedades de un lector real que negocia significados. Del análisis cultural marxista sustraen el reconocimiento de la resistencia, la oposición y la subversión. Y de la teoría de medios, los autores le dan prominencia al espectador activo, selectivo e informado. Todos y cada uno de estos atributos constituyen las propiedades de su propuesta.

La última aproximación que describe un conjunto de procesos es la de Liebes (1996). Esta propuesta describe las formas de involucramiento del individuo con los contenidos de la televisión, las cuales resultan de las dos dimensiones que se discuten en esta aproximación: la abierta o la cerrada, y la referencial o la construccional. Las variables resultantes de las diversas combinaciones de estas dimensiones son la real, la ideológica, la lúdica y la estética. La referencial y la cerrada definen la real. El individuo que se sitúa en esta variable se involucra, de forma incondicional, con los hechos y las situaciones de los personajes en los contenidos. De igual manera, traslada esos hechos y situaciones a su vida diaria.

La referencial y la abierta definen la lúdica. El individuo en esta variable rehace la historia mediada y los elementos en ella. Al restablecerla, intenta amalgamar las nuevas situaciones y los personajes a su vida cotidiana sin vislumbrar en detalle el contenido de la historia modificada. El individuo lo que intenta es jugar con los elementos de la historia mediada para la historia nueva o modificada. La variable ideológica considera el juicio del individuo en el momento de involucrarse con lo mediado. El individuo reflexiona respecto de lo mediado y reacciona de una manera informada, dilucidando las características del contenido de lo televisado. Esta variable es determinada por las dimensiones construccional y cerrada. 
Finalmente, se encuentra la variable estética. Esta es similar a la ideológica en el hecho de que en ambas hay todo un proceso de reflexión del individuo. Sin embargo, la variable estética se distingue de la ideológica en la manera en que reacciona el individuo. Si bien en la variable anterior el individuo reconoce que hay un significado oculto de un metatexto, en la variable estética el reconocimiento de la hegemonía queda de lado. Se centra más en vislumbrar la reacción del individuo respecto de las características del contenido en lo mediado. El "construccional/abierto vuelve a ser el más juguetón de los dos, por lo que los espectadores disciernen los bloques de construcción estéticos de los cuales la narrativa se compone y muestran su capacidad para construir alternativas" (Liebes, 1996, p. 39).

Sobre la línea de estudio que analiza la relación entre los individuos pertenecientes a minorías, o diásporas, y los medios y su contenido, la literatura es considerable (cf. Bailey, 2007; Bennett et al., 2006; Gumpert y Drucker, 2007; Lee y Cho, 1990; Levo-Henriksson, 2007; Robins y Aksoy, 2005; Robins y Aksoy, 2006). Cada una de las investigaciones ayuda a entender distintos momentos del proceso de domesticación. Desde la perspectiva de la apropiación, Bailey (2007) argumenta que, del grueso de la población inglesa, las minorías son las que consumen más productos mediáticos extranjeros. Hecho que se distingue en su consumo de películas en las salas de cine y con su renta a través de locatarios concesionarios.

Lee y Cho (1990) y Gumpert y Drucker (2007) contribuyen a entender el momento de la objetivación. En sus estudios describen la generación de espacios por minorías en los Estados Unidos para el consumo de aparatos electrónicos y textos mediados. En ellos muestran la identificación de miembros de minorías con líneas rutinarias de pensamiento y acción afines a su cultura. En este sentido, parecen contribuir también al concepto de 'proximidad cultural'. Straubhaar (2003) define este concepto como la manera en que una categoría de individuos se identifica con el texto audiovisual en un contexto de movilidad.

Bennett et al. (2006), por otro lado, sugieren características del momento de la incorporación entre miembros de grupos minoritarios 
en Inglaterra. Los autores argumentan que los grupos minoritarios son los que más contratan televisión de paga, y los que más consumen horas frente a la pantalla tanto de salas de cine como de televisión o de computadora. Además, los miembros de estos grupos parecen tener una identificación más estrecha con productos culturales de Australia y los Estados Unidos por sus preferencias en el momento de elegir.

Robins y Aksoy (2005, 2006) y Levo-Henriksson (2007), finalmente, contribuyen a ilustrar el momento de la conversión. Ambos muestran información similar, pero desde distinta perspectiva. Por un lado, Robins y $\operatorname{Aksoy}(2005,2006)$ muestran datos que determinan la relación entre el individuo y el texto audiovisual. Estos autores argumentan que, aunque la información transmitida en los noticieros televisivos ingleses es contraproducente para las minorías turcas, también hay oferta de productos culturales favorables, lo cual es celebrado por los miembros de este grupo. Por otro lado, Levo-Henriksson (2007) proporciona información que establece la relación entre el individuo y el objeto mediático. Este autor describe la manera y los fines para los que es utilizada la radio por los miembros de la etnia hopi. El estudio revela que, si bien la radio es utilizada como un medio de comunicación para la comunidad hopi, también sirve como medio de poder para el reforzamiento de su identidad como grupo.

\section{Neoinstitucionalismo}

La idea principal del neoinstitucionalismo, relacionada con la interacción entre el individuo y el texto audiovisual, sugiere la existencia de líneas rutinarias de pensamiento y acción que se instituyen y difunden con los medios de comunicación tradicional y las nuevas tecnologías en todo el mundo (Drori, Meyer y Hwang, 2006). Se refiere, por un lado, a la cristalización de líneas rutinarias de pensamiento y acción a través del texto audiovisual y, por otro lado, a la difusión de dichas líneas rutinarias de forma global. El argumento central para la consolidación de estos objetivos se encuentra en la forma de organizarse de las instituciones sociales (Antola y Rogers, 1984; Meyer, et al., 1997; Thomas, 2007), así como en las características de las ideas que se difunden de forma global (Hernández, 2001; Simmons, Dobbin y Garrett, 2008; Wilkinson, 2003). 
Thomas (2007) identifica ocho tipos de actores principales que desempeñan un papel determinante en la institución de líneas rutinarias de pensamiento y acción en el individuo. Habla de los Estados nación, las organizaciones gubernamentales internacionales, las instituciones económicas, las Naciones Unidas, los tribunales y las cortes internacionales, las organizaciones no gubernamentales internacionales, algunos individuos como tal y las corporaciones transnacionales. La manera en que operan estos actores está ligada a una suerte de ontología que responde principalmente a cuatro características (Meyer, et al., 1997): isomorfismo, agencia racional, desacoplamiento y estructuración expansiva.

En las corporaciones transnacionales de medios, por ejemplo, Antola y Rogers (1984) analizan el flujo de programas televisivos entre las naciones latinoamericanas y los Estados Unidos. La evidencia empírica arrojada por dicho estudio deja entrever un sensible incremento en el flujo de comunicación entre los países de la región latinoamericana, comparado con un estudio similar realizado tiempo atrás por Nordenstreng y Varis (1974). Si bien Antola y Rogers demuestran que hay una sensible modificación en el flujo entre países, la situación no parece ser tan alentadora porque las estructuras de las industrias culturales latinoamericanas emulan lo que las industrias estadounidenses realizan, pero sin tener el mismo éxito. Desde que las condiciones en que lo realizan son distintas de aquellas que enfrentan las industrias culturales de países desarrollados, lo único que se produce es una especie de desacoplamiento. Es decir, lo que ocurre es que se imita un modelo sin considerar las condiciones distintas del lugar en que se implementa.

No obstante, aun con el producto del desacoplamiento con la emulación de modelos, las industrias culturales de países en vías de desarrollo transmiten contenidos de países desarrollados, con lo cual provocan una forma de asimetría en el flujo de programas televisivos entre países de distinto tipo (Straubhaar, 1991) y la cristalización de líneas rutinarias de pensamiento y acción de un grupo de países desarrollados (Nordenstreng y Varis, 1974). Berger y Huntington (2002) sugieren, en este sentido, lo que se denomina las dinámicas culturales de la globalización. Se refieren 
a mecanismos de dosificación que organizan las diferencias y las disyuntivas de los que las consumen. Entre ellas se encuentran: la cultura de Davos, la cultura de las organizaciones no gubernamentales, la cultura del movimiento transnacional producido por el pentecostalismo y la cultura popular del entretenimiento y el consumo. Esta última desempeña un papel preponderante en la cristalización de líneas rutinarias de pensamiento y acción con el texto audiovisual.

Por otro lado, se encuentra el hecho de la difusión de líneas rutinarias de pensamiento y acción en todo el mundo. Simmons, Dobbin y Garrett (2008) identifican cuatro mecanismos con los cuales se difunden las ideas de forma global: coerción, competencia, aprendizaje y emulación. Hoskins, Mirus y Rozeboom (1989), por ejemplo, argumentan un acomodo de los contenidos de los productos culturales de países en vías de desarrollado en el mercado. Las estrategias de distribución y venta de las corporaciones transnacionales de estos últimos países hacia el exterior producen una serie de restricciones para los productos de países en vías de desarrollo. Esto provoca, por un lado, presión en los compradores potenciales para la transmisión de productos culturales de países en vías de desarrollado en televisoras nacionales y, por el otro, la disminución de inversiones en la producción de contenidos culturales locales. Así se produce lo que Simmons, Dobbin y Garrett (2008) denominan "mecanismo de coerción".

Hernández (2001) y Wilkinson (2003) nos ofrecen ejemplos de difusión con el texto audiovisual, particularmente del contenido de las telenovelas latinoamericanas. Con ellas parecen describir lo que Simmons, Dobbin y Garrett (2008) denominan “mecanismo de aprendizaje”. Si bien su análisis se apoya en aseveraciones económicas, logran develar el origen, el desarrollo y el flujo del contenido melodramático de este género. Al describir la manera en que se consolidan las narrativas o los libretos de las telenovelas, desde la perspectiva del que las produce, logran entrever el amalgamiento de ideas. Y en ese sentido la difusión de ideas entre países productores de este género. Es decir, la manera en que productores locales adoptan creencias exógenas y las implementan en sus contenidos culturales. Lo que clarifica, por un lado, los mecanismos de difusión y, por otro, la cristalización de líneas rutinarias de pensamiento y acción. 
De acuerdo con Thussu (2007, p. 25), "el desequilibrio entre los flujos globales dominantes, subalternos y geo-culturales refleja las asimetrías en los flujos de ideas y bienes". Este mismo autor propone una tipología distinta para sustituir los términos flujo dominante y contraflujo por los de flujos: global, transnacional y geocultural. Los flujos globales se refieren a los ya conocidos flujos dominantes de productos culturales de origen estadounidense, los cuales caracterizan lo que Meyer et al. (1997) identifican como estructuración expansiva, y lo que Simmons, Dobbin y Garrett, (2008) entiende como mecanismo de coerción. Los flujos transnacionales, por otro lado, se refieren a la localización, o desacoplamiento, de productos culturales estadounidenses; por ejemplo: CNN en español, MTV Latinoamérica o Fox Sports Americas. Este desacoplamiento se lleva a cabo, principalmente, con la adecuación de los libretos de los productos audiovisuales de países centrales a las audiencias de países de la periferia.

El flujo geocultural, finalmente, se refiere a los ya denominados contraflujos subalternos llevados a cabo por países periféricos; por ejemplo: el anime japonés, las telenovelas mexicanas, venezolanas y brasileñas, o las películas bollywoodenses de origen hindú. Estos contraflujos son singulares porque tratan de distanciarse de los mecanismos de difusión (Hoskins, Mirus y Rozeboom, 1989) de los países centrales, aunque implementando las mismas características organizativas (Meyer et al., 1997). En ese sentido, si bien se ha diversificado la manera en que fluyen los productos de las industrias culturales y creativas (Flew, 2013), las disparidades en el volumen y el valor económico de los productos de países centrales también se han resaltado porque el contraflujo de productos culturales de países de la periferia es aún mucho menor y se mantiene concentrado en ciertas regiones del mundo en comparación con el resto de los productos de los países centrales.

\section{Datos y metodología}

Una de las formas para aproximarse a la adecuación de líneas rutinarias de pensamiento y acción mediadas por el individuo es con las entrevistas narrativas porque permiten visualizar la interacción entre el individuo y los relatos audiovisuales y porque posibilitan utilizar las herramientas del aná- 
lisis del discurso. A diferencia de un estudio previo con jóvenes en Monterrey, en el que se utiliza la técnica de investigación de entrevistas focalizadas (Miranda, 2011), el enfoque adoptado en este estudio es completamente inductivo, lo cual quiere decir que no hay una estructura definida para el desarrollo de las entrevistas. Dado que el objetivo era visualizar las adecuaciones de las líneas rutinarias por el individuo de forma natural, nunca se pensó en predeterminar o sugerir temáticas precisas. Simplemente se dejó que fluyera la información del informante respecto de su vida diaria.

El universo de mi muestra comprendió la categoría de individuos jóvenes pertenecientes a grupos étnicos y que migraron a Monterrey. De acuerdo con el censo de población y vivienda 2010 (Instituto Nacional de Estadística y Geografía [Inegi], 2015), en Monterrey había 1135550 habitantes, de los cuales 11382 eran una población de 5 y más años que hablaba lengua indígena. De esta población entrevisté a jóvenes entre los 17 y los 25 años que pertenecen a las comunidades étnicas náhuatl y mixteca.

Puesto que el objetivo de la investigación era vislumbrar la manera en que líneas rutinarias de pensamiento y acción mediadas son adecuadas por una categoría de individuos, se optó por seleccionar individuos con características más o menos uniformes. Por un lado, por su condición de movilidad de su lugar de origen a una gran urbe, en este caso a Monterrey. Por otro lado, para vislumbrar de forma más precisa la adecuación de líneas rutinarias mediadas. $Y$, finalmente, para prescindir de la definición de cultura como algo fijo, y acentuar la posibilidad de una cultura del mundo en estado emergente.

Recolecté información con la técnica de investigación de entrevistas narrativas (Benwell y Stokoe, 2006, p. 141), mediante un modelo de recolección de datos inductivo. Durante el desarrollo de las entrevistas hice hincapié en la elaboración de narrativas a partir de seis distintas situaciones de la vida diaria de mis informantes. Las seis situaciones a las que presté particular atención fueron divididas en dos distintos momentos: su infancia y su situación actual en el momento de la entrevista. Las narraciones de la infancia son acerca de una anécdota vivida en la etapa de la niñez y una anécdota recordada, mas no vivida en carne propia, también de su niñez. Y 
las de la situación actual en el momento de la entrevista incluyen una historia mediada por los medios de comunicación tradicionales o las nuevas tecnologías y una historia no mediada, todas ellas en distinto orden. La información fluyó según la disponibilidad y el asentimiento de los entrevistados para compartirla.

El tipo de muestreo que utilicé fue no probabilístico (Hernández, Fernández-Collado y Baptista, 2006, p. 241). Seleccioné a mis informantes a través de un par de instituciones que trabajan con la categoría de individuos antes mencionada. Este par de instituciones tienen por nombre Árbol de Todas las Raíces A. C. y Asociación Zihuame Mochilla A. C., y tienen su sede en Monterrey, Nuevo León, México. Aunque estas instituciones realizan actividades distintas, ambas se especializan en ofrecer información y capacitación a los jóvenes pertenecientes a grupos étnicos y que migraron a la gran urbe, por lo cual la selección de mis informantes la realicé basado en los individuos que asisten a dichas instituciones.

La justificación del muestreo tiene que ver con el enfoque inductivo adoptado en la presente investigación. En particular, tiene que ver con la técnica de investigación de entrevistas narrativas. Desde que mi objetivo era adentrarme en la vida diaria de los informantes y aminorar mi distancia respecto de ellos en función del rapport, decidí acudir a las instituciones antes mencionadas. De esta forma, logré vivenciar, de forma plena, no solo la intrínseca relación entre ellos como individuos y las instituciones como actores importantes en su vida diaria, sino también la interacción entre ellos y el relato audiovisual mediado, con experiencias facilitadas por las instituciones en distinto momento y por algunos de los individuos de forma particular. Finalmente, también sirvió para conocer un poco más el contexto cultural en el que se desarrollan y delimitar las líneas rutinarias de pensamiento y acción de su vida diaria.

Desde que este estudio ha sido conducido desde una perspectiva construccionista (Alasuutari, 1995), lo que prevalece es la proporción de información adquirida con la técnica de investigación utilizada. Como ya se había dicho, la recolección de datos fue realizada con la técnica de investigación de entrevistas narrativas. La base de datos comprende un aproximado 
de 25 horas de grabación que resultan en unas 600 cuartillas de transcripción. De ahí se seleccionaron los extractos de las entrevistas originales para mostrarse en el apartado de resultados.

Previamente a las entrevistas, se estableció un rapport con los informantes (Taylor y Bogdan, 1987) al impartir talleres y participar activamente en las actividades organizadas por el par de instituciones que facilitaron el trabajo de campo. Desde que la aproximación al fenómeno de estudio fue inductiva, se optó por iniciar la entrevista preguntando sobre la última actividad que el informante había realizado el día anterior. Después, se le pidió que profundizara en su descripción de las actividades que había hecho durante todo ese día. Más tarde, se le solicitó que describiera sus actividades de lunes a viernes. Finalmente, se le pidió que hiciera una descripción similar a la solicitada para los días de entresemana, pero ahora para los días del fin de semana: sábado y domingo.

Una vez descrita su rutina diaria de la semana, se le solicitó al informante que describiera sus actividades, pero ahora durante las vacaciones. La descripción de las rutinas diarias, en una semana convencional y una de vacaciones, dio pie a identificar la interacción de los informantes con los medios de comunicación, las nuevas tecnologías y sus contenidos. Esto detonó y agilizó la respuesta al requerimiento de narrar un relato audiovisual del cual se acordaran. El orden de las entrevistas fue distinto en cada caso, y la selección del relato fue a libre albedrío de los informantes, quienes narraron relatos audiovisuales de su preferencia. La clasificación de las respuestas para este escrito se hizo en función de la pregunta de investigación; es decir, en relación con la manera en que se da la interacción entre jóvenes pertenecientes a grupos étnicos y que migraron a Monterrey, y algunos relatos audiovisuales extranjeros de ficción que consumen.

\section{Resultados}

Cuando se habla del consumo de los medios de comunicación, se habla por implícito de la interacción entre el individuo y el relato. ${ }^{3}$ Para entender esta

3 El relato es el producto de la narración, y puede ser oral, escrito, audiovisual o interactivo para comunicar una historia a otros. El relato audiovisual se caracteriza por utilizar imágenes y audios, tiene personajes y generalmente tiene un final; por ejemplo: una serie televisiva, una película convencional o de dibujos animados (anime) o una telenovela. 
interacción en un contexto de movilidad, el consumo mediático de los jóvenes pertenecientes a grupos étnicos y que migraron a Monterrey es un ejemplo. Sus narraciones acerca de algunos relatos audiovisuales que consumen evocan referencias relacionadas con su contexto inmediato. En este artículo, se sugieren seis tipos de referencias según sus relatos: a códigos de conducta o normas morales del hogar, al perfil de uno de los actores en semejanza al perfil del consumidor, a instituciones en el contexto local inmediato, a situaciones de la vida cotidiana, a prácticas del género femenino y a la comparación internacional.

La referencia a códigos de conducta o normas morales del hogar es evidente, pero en ocasiones difícil de identificar o reconocer. Se trata de la relación entre los códigos de conducta del relato audiovisual y los códigos de conducta del consumidor. Aquí regularmente el consumidor realiza juicios de valor respecto de las situaciones que a su consideración parecen inaceptables para los códigos de conducta o normas morales de su hogar.

Educando a mamá me gustó y se la recomendé a la maestra de Psicología porque todo lo que habla es psicológico. Es una chavilla que vive sola con su mamá, pero su mamá no le presta la atención que se debe tener a un hijo. Resulta que la chavilla se entristece porque su mamá nada más ve por ella misma. Y su mamá tiene una relación, pero tiene una relación con una persona casada. Y ella (la chavilla) le dice que por qué tiene esa relación si sabe que no va a obtener nada de ahí. ${ }^{4}$

La segunda se refiere a cuando el consumidor se identifica a sí mismo y a sus semejantes con el/los perfil/es de los actores o personajes del relato audiovisual. En las referencias al perfil de uno de los actores en semejanza al perfil del consumidor, los espectadores se colocan en distintas posiciones respecto de los actores o personajes en cuestión.

Me gustó mucho porque me la enseñó una amiga, y se trata de dos amigas que se llaman Nana. Las dos. Pero se apellidan diferente, y las dos son diferentes. Una es muy tímida y sensible. Se vestía con vestidos rosas. La otra era roquera, cantaba y era como muy machista. 0 sea, no machista, pero se comportaba como un hombre.

4 Educando a mamá (2012), [película], Riggen, P. (dir.), Estados Unidos, Anxiety Productions, Latitude Entertainment, Pantelion Films. 
Pero era mujer y le gustaban los hombres. No era bisexual. Y nos gustó mucho porque nos identificábamos con ellas. Me identificaba con la que era más ruda; la más normal. La otra era muy sensible, lloraba por todo y me caía muy mal. Las dos tenían cosas que nos gustaban, y por eso la veíamos. De la primera me gustaba que era sensible y platicaba mucho. Pero no me gustaba que fuera muy frágil. Confiaba mucho en las personas, y le faltaba mucha inteligencia. Se comportaba como una niña. La otra era más inteligente; razonaba más. A pesar de las cosas feas que le pasaban, ella seguía adelante..$^{5}$

La tercera se refiere a cuando el consumidor menciona por sustitución instituciones situadas en su contexto inmediato. El consumidor relaciona las situaciones de los contenidos de los medios con instituciones religiosas o educativas en el ámbito local. La referencia a las instituciones en el contexto local inmediato no siempre es explícita. Sin embargo, el hecho de mencionar elementos pertenecientes a esas instituciones es considerado como una sugerencia potencial.

\begin{abstract}
[...] hay otras películas en las que los personajes, muchachos 0 señoras se enfrentan a situaciones 0 animales salvajes. Y, al final, logran sobrevivir. Por eso es lo que yo decía, a veces veo a uno y lo identifico conmigo, con mi familia; con mi papá o mamá. Yo me he enfrentado a animales salvajes. Por ejemplo, a una serpiente. Nosotros vemos ese hecho relacionado con lo que es el mal. Como nosotros somos de una familia cristiana, el mal es el diablo. 0 también se puede transformar en distintas cosas. En la Biblia se menciona que el mal es un león rugiente que anda por todos lados. Igual, la serpiente que ve a Adán y a Eva. ${ }^{6}$
\end{abstract}

Las referencias a situaciones de la vida cotidiana se asemejan mucho a la categoría de instituciones en el contexto local inmediato. Lo distinto es que en este caso se hace referencia explícita a situaciones o hechos en los que el consumidor se ve involucrado con objetos o sensaciones provocadas por su alrededor. En ese sentido, ninguna institución participa. Él/ ella vincula los hechos o situaciones del relato audiovisual con los hechos o situaciones de su vida cotidiana.

5 Nana (2006), [serie de TV], Morio Asaka, Ryosuke Nakamura, Tsuyoshi Matsumoto (dirs.), Japón, Madhouse Studios.

6 La huérfana (2009), [película], Collet-Serra, J. (dir.), Estados Unidos, Appian Way, Dark Castle Entertainment, Silver Pictures. 
Además de ser los más guapos y ricos de Corea, uno tiene una fundación porque hace barros y es el más famoso a su corta edad. Estudió en el INSUCO 0 TEC. Uno es el jefe de la mafia; de los malos de todo el mundo. El otro es dueño de casi la mitad de la escuela Shinhwa. Y el otro tiene una fundación con su abuelo. Su abuelo es expresidente. ${ }^{7}$

La niña se fue en el carro al agua, y se ahogó. La señora no se ahogó. Ella sí logro salir, y ahí terminó la película. Me gustan las películas de terror porque ahí veo qué cosas son reales y qué cosas no. Y he aprendido a no tener miedo. A enfrentarme a las cosas que pasan sin que suceda algo malo. En mi vida he pasado cosas feas y cosas bonitas. Por eso me identifico con las películas de terror. Las cosas malas pasan, pero si logramos superarlas vienen las cosas buenas. $Y$ eso es lo que me gusta. Por ejemplo, cuando yo estaba en la secundaria, mi mamá se iba a aliviar. Por la casa pasa un río; en ese tiempo estaba supercrecido. Y había que cruzarlo para ir por la partera. Mi papá me dijo que lo acompañara. Fui la única que fui por la partera. Y todos me preguntaban si no había tenido miedo al pasar. Entonces, las películas de terror me enseñan a no tener miedo. En este caso, nadie se atrevía a cruzar el río por miedo a que el bote se volteara. ${ }^{8}$

La referencia a prácticas del género femenino se refiere a situaciones en las que los consumidores mencionan características que a su parecer son atribuibles al género femenino. Por ejemplo, el hecho de que las personas del sexo femenino lloren, pierdan su virginidad para ser consideradas mujeres o realicen tareas en el espacio físico del hogar que las llevé a ser denominadas como amas de casa.

Cuando se fue Ren, él se la (a Nana Osaki) quería llevar. 0 sea, él se la quería llevar a Tokio. Pero sabía que Nana era demasiado orgullosa y no se iba a ir con él. Nana (Komatsu) pensaba eso, y luego le dijo que por qué no se iba con Ren. Ella le dijo que ella no pensaba en ir a Tokio, y en que le comprara un departamento y todas las tardes se sentara a esperarlo con Ramen. 0 sea, no quería ser una ama de casa. Él iba a ir a tocar con el grupo. Ella tocaba por su cuenta. Él ya tenía una vida. Nana no tenía nada. Ella tocaba porque Ren le enseñó. Si no le hubiera enseñado, ella no sabría tocar. ${ }^{9}$

7 Boys Before Flowers (2009), [serie de TV], Jeon Gi-sang (dir.)., Corea del Sur, Group Eight.

8 La huérfana (2009), [película], Collet-Serra, J. (dir.), Estados Unidos, Appian Way, Dark Castle Entertainment, Silver Pictures.

9 Nana (2006), [serie de TV], Morio Asaka, Ryosuke Nakamura, Tsuyoshi Matsumoto (dirs.), Japón, Madhouse Studios. 
La sexta referencia, comparación internacional, se da cuando el consumidor habla sobre instituciones religiosas, grupos étnicos o individuos de otra nacionalidad, los cuales se encuentran fuera de su contexto local inmediato. Estas instituciones o categorías de individuos desempeñan un papel preponderante en el comparativo entre las características de los consumidores con las de los actores o personajes en el relato audiovisual:

Mi amiga me comentaba cómo eran los musulmanes. Me decía que tenían siete esposas. Que no tenían permiso de estar muy destapadas. Que tenían que estar muy bien tapadas. Que eran muy religiosas. Que sus matrimonios eran arreglados. Que tenían mucho oro, y sus esposos eran muy ricos. Y que si cometían un pecado, eran castigados con 70 latigazos. Entonces, yo decía, qué raros. Una vez, un profesor hizo un comentario. Que los musulmanes tenían religiones muy raras. Que tenían siete esposas, y que las esposas se cubrían el cuerpo por completo. Y ya cuando vi la novela, fue cuando vi cómo eran. ¡No sé si todo eso sea realmente así! Es parecido a las costumbres de la comunidad. De la comunidad de nosotros. De la mía; comunidad mixteca. Que las mujeres no tenían derecho a casi nada. Tenían que ser muy sumisas, y estar casi siempre bien tapadas. Con faldas, es decir, no tan extravagantes. Pero si es una blusa, tenía que estar con cuello; sin descubrirse más de lo debido. Los matrimonios arreglados, y así. Era lo que yo hacía comparación. Actualmente es así en mi comunidad, pero ya no tanto. Hay una que otra familia que sigue teniendo los mismos pensamientos. Pero mi generación ya no. ${ }^{10}$

Se llama María. A su hermana la vendieron en la colonia Héctor Caballero. El chavo vio a la chava. La vio, le gustó y fue y la pidió a su casa. Luego ellos (su familia) dijeron que sí, pusieron cantidad, y ahora están esperando la fecha. Ella no quería, pero sus papás le dijeron que era lo mejor. Que era peor si se quedaba sola. Él quería casarse primero con mi hermana. Fue a la casa a pedirla. Pero como mi familia es diferente, le preguntaron a mi hermana si se quería casar con él. Y ella dijo, "no". Y el chavo aun así la buscaba. Le decía que si era porque no la conocía, que ella dejara que le hablara para que la conociera. Luego él fue a pedir a la otra muchacha, y dijeron "sí". Entonces, arreglaron el casamiento de la otra muchacha. $Y$ ahora se van a casar. ${ }^{11}$

10 El clon (2010), [serie de TV], Cruz, M. y Restrepo, A. (dirs.), México, Telemundo Network.

11 El clon (2010), [serie de TV], Cruz, M. y Restrepo, A. (dirs.), México, Telemundo Network. 


\section{Conclusiones}

La pregunta que guía la presente investigación está ligada con las maneras en que interactúa el individuo con el relato audiovisual. Este estudio se enfoca en analizar las narraciones producto de la experiencia de los individuos en condición de movilidad con el contenido de los medios de comunicación. Otro de los propósitos es discutir si existe o no una cultura del mundo emergente o persiste la figura de la diversidad cultural, según el neoinstitucionalismo y el marco de la domesticación, respectivamente.

Si fuera por el origen del contenido de los relatos audiovisuales que consumen los jóvenes de origen étnico entrevistados, diríamos que hay indicios de una cultura del mundo según el neoinstitucionalismo. Esta teoría argumenta la existencia de líneas rutinarias de pensamiento y acción que se instituyen y difunden con el contenido de los medios de comunicación (Drori, Meyer y Hwang, 2006). El hecho de que esta categoría de jóvenes haya narrado en su mayoría relatos de origen estadounidense sugiere dos cosas. Por un lado, la idea de un mecanismo de coerción en la distribución y la venta de productos culturales de países desarrollados al exterior (Simmons, Dobbin y Garrett, 2008) y, por otro, la cristalización de líneas rutinarias de pensamiento y acción a través de la cultura popular del entretenimiento y el consumo (Berger y Huntington, 2002).

No obstante, la idea anterior no parece ser tan fructífera si se analiza de cerca la interacción entre el individuo y el texto audiovisual; es decir, si se analizan las referencias a esos contenidos por parte de los informantes de esta investigación. En el contexto de la domesticación, este análisis se refiere al momento en que el consumidor relaciona el texto audiovisual con el espacio físico que lo rodea. Este momento se denomina objetivación.

Por un lado, hay una similitud entre lo que Gurevitch, Levy y Roch (1991) denominan la domesticación de lo foráneo con lo que encontramos en las referencias de los informantes. Aunque esa investigación muestra la domesticación de lo foráneo en el texto noticioso, en esta investigación se identifican prácticas similares, pero en el consumo de relatos audiovisuales 
por parte de los jóvenes de origen étnico entrevistados porque estos jóvenes trasladan ideas de lo estrictamente público a lo privado y luego nuevamente a lo público considerando su contexto inmediato en el espacio físico atribuido al relato. Si bien nada se puede decir del contenido en sí del relato audiovisual, sí se puede argumentar respecto de su consumo por parte de dichos jóvenes porque las narraciones de los jóvenes a partir de los relatos sugieren la construcción de significados que son compatibles con su cultura y su ideología.

Por otro lado, si consideramos las aportaciones de Hall (1980), Livingstone y Lunt (2002) y Liebes (1996) en el momento de la objetivación del marco de la domesticación, parece que cada uno de estos enfoques puede ser ilustrado con las referencias de nuestros informantes a los relatos audiovisuales que consumen. Los jóvenes entrevistados en ocasiones legitiman las líneas rutinarias de pensamiento y acción contenidas en el relato audiovisual, pero modifican el significado a su manera de forma que lo hacen asequible a la cultura y la ideología que les rodeo, tal como lo sugiere el código negociado de Hall. En otras ocasiones, realizan juicios evaluativos respecto de lo que les gusta o disgusta del relato, como lo haría el espectador crítico de Livingstone y Lunt. Finalmente, estos jóvenes a veces reconstruyen completamente el relato, de manera tal que le dan un significado totalmente distinto del esperado, lo cual nos remite a Liebes y sus maneras lúdicas e ideológicas de ver la televisión.

De acuerdo con los hallazgos empíricos de Lee y Cho (1990) y Gumpert y Drucker (2007), y el concepto de 'proximidad cultural' de Straubhaar (2003), los resultados de la presente investigación dejan entrever una contribución al concepto, pero desde la perspectiva del individuo y no del relato audiovisual. Si bien hay una proximidad cultural de los jóvenes entrevistados al texto audiovisual, esta es dada por ciertos elementos que corresponden en ocasiones justo al cambio de significación o a la reconstrucción del relato, y no a elementos en sí del texto audiovisual.

Castelló (2010) señala que la proximidad cultural no solo es provista por una apelación a la nación, a la cultura o al lenguaje, sino también por 
elementos educativos, cognitivos y emocionales, y por aspectos relacionados con el entorno inmediato de la audiencia. Las referencias de los jóvenes entrevistados a algunos de los textos audiovisuales que consumen sostienen esto último. La proximidad cultural de estos jóvenes al texto audiovisual parece estar más ligada a su visión y su posición como espectadores que al contenido de la historia.

Finalmente, los hallazgos de esta investigación sugieren la idea de una diversidad cultural más que de una cultura del mundo emergente. Si bien requiere más tiempo ponderar las narraciones de los informantes con precisión, las referencias a valores, normas de conducta o situaciones de la vida cotidiana son evidentes y preponderantes porque los informantes mencionan intensamente estas referencias en sus narraciones en función del relato audiovisual mediado que consumen. Por otro lado, las referencias sostienen que esta categoría de individuos resignifican y construyen los relatos audiovisuales que consumen, de manera tal que la ideología y la cultura dominante se manifiestan principalmente en el acontecer de los informantes y no con el texto audiovisual.

\section{Referencias}

Alasuutari, P. (1995). Researching culture: Qualitative method and cultural studies. Londres: Sage.

Alasuutari, P. (2004). Social theory and human reality. Londres: Sage.

Alasuutari, P., Qadir, A. y Creutz, K. (2013). The domestication of foreign news: news stories related to the 2011 Egyptian revolution in British, Finnish and Pakistani newspapers. Media, Culture \& Society, 35(6), 692-707.

Althusser, L. (1971). Lenin and philosophy and other essays. Londres: Monthly Review Press.

Antola, L. y Rogers, E. M. (1984). Television flows in Latin America. Communication Research, 11(2), 183-202. 
Bailey, O. G. (2007). Transnational identities and the media. En O. Bailey, M. Georgiou y R. Harindranath (eds.), Transnational lives and the media (pp. 212-230). Nueva York: Palgrave Mcmillan.

Bennett, T., Savage, M., Silva, E., Warde, A., Gayo-Cal, M. y Wright, D. (2006). Media culture: the social organisation of media practices in contemporary britain. British Film Institute.

Benwell, B. y Stokoe, E. (2006). Discourse and identity. Edimburgo: Edinburgh University Press.

Berger, P. L. y Huntington, S. P. (2002). Many globalizations: Cultural diversity in the contemporary world. Nueva York: Oxford University Press.

Boli, J. y Thomas, G. (1997). World culture in the world polity: A Century of international non-governmental organization. American Sociological Review, 62, 171-190.

Campbell, C. (1992). The desire for the new its nature and social location as presented in theories of fashion and modern consumerism. En E. Hirsch y R. Silverstone (eds.), Consuming technologies (pp. 4458). Londres: Routledge.

Castelló, E. (2010). Dramatizing proximity: Cultural and social discourses in soap operas from production to reception. European Journal of Cultural Studies, 13(2), 207-223.

Cohen, J. (2002). Deconstructing Ally: Explaining viewers' interpretations of popular television. Media Psychology, 4(3), 253-277.

Drori, G. S., Meyer, J. W. y Hwang, H. (2006). Introduction. En Globalization and organization: World society and organizational change (pp. 1-22). Oxford, UK: Oxford University Press.

Flew, T. (2013). Global creative industries. Cambridge, UK: Polity Press. 
Georgiou, M. y Silverstone, R. (2007). Diasporas and contra-flows beyond nation-centrism. En D. Thussu (ed.), Media on the move (pp. 3043). Londres: Routledge.

Gumpert, G. y Drucker, J. (2007). Diaspora: An urban communication paradigm. En O. Bailey, M. Georgiou y R. Harindranath (eds.), Transnational lives and the media (pp. 195-211). Nueva York: Palgrave Mcmillan.

Gurevitch, M., Levy, M. y Roch, I. (1991). The global newsroom: Convergences and diversities in the globalization of television news. En P. Dahlgrem y C. Spark (eds.), Communication and citizenship: Journalism and the public sphere in the new media age (pp. 195-216). Londres: Routledge.

Hacker, K. L., Coste, T. G., Kamm, D. F. y Bybee, C. R. (1991). Oppositional readings of network television news: viewer deconstruction. Discourse \& Society, 2(2), 183-202.

Hall, S. (1980). Encoding/decoding. En S. Hall, D. Hobson, A. Lowe y P. Willis (ed.), Culture, media, language (pp. 128-38). Londres: Hutchinson.

Hernández, O. D. (2001). A case of global love (Disertación inédita). Universidad de Texas en Austin, Estados Unidos de América.

Hernández, R., Fernández-Collado, C. y Baptista, P. (2006). Metodología de la investigación (4. ${ }^{a}$ ed.). México: McGraw-Hill Interamericana.

Hoskins, C., Mirus, R. y Rozeboom, W. (1989). US television programs in the international market: Unfair pricing? Journal of Communication, 39(2), 55-75.

Instituto Nacional de Estadística y Geografía (Inegi) (2010). México en cifras. Recuperado el 17 de noviembre de 2014 de http://www3.inegi.org.mx $/$ sistemas $/$ mexicocifras $/$ default.aspx? src $=487 \& \mathrm{e}=19$ 
Jenks, C. (2005). Culture. Nueva York: Routledge.

Lechner, F. y Boli,J. (2005). World culture: Origins and consequences. Oxford, UK: Blackwell Publishing.

Lee, M. y Cho, C. H. (1990). Women watching together: An ethnographic study of Korean soap opera fans in the US. Cultural Studies, 4(1), 30-44.

Levo-Henriksson, R. (2007). Media and ethnic identity: Hopi views on media, identity, and communication. Nueva York: Routledge.

Liebes, T. (1996). Notes on the struggle to define involvement in television viewing. Réseaux. The French Journal of Communication, 4(1),35-46.

Liebes, T.y Katz, E. (1990/2007). The export of meaning: Cultural readings of Dallas. Cambridge: Blackwell Publishers.

Livingstone, S. y Lunt, P. (2002). Talk on television: Audience participation and public debate. Londres: Routledge.

Martínez Garza, F. J. (2005). La oferta de televisión en América Latina: hacia un análisis de flujos. Zer, Revista de Estudios de Comunicación, 19, 145-172.

Meyer,J. (2010). World Society, institutional theories, and the actor. Annual Review of Sociology, 36, 1-20.

Meyer, J. W., Boli, J., Thomas, G. M. y Ramirez, F. O. (1997). World society and the nation-state. American Journal of Sociology, 103(1), 144-181.

Miranda, O. (2011). Diversidad de exposición de jóvenes neoleoneses, guanajuatenses y quintanarroenses a la televisión y al cine. Comunicación y Sociedad, 16, 161-183. 
Morley, D. y Silverstone, R. (1990). Domestic communication. Media, Culture \& Society, 12, 31-55.

Nordenstreng, K. y Varis, T. (1974). Television traffic: A one-way street. Reports and Papers on Mass Communication, 70.

Qadir, A. y Alasuutari, P. (2013). Taming terror: domestication of the war on terror in the Pakistan media. Asian Journal of Communication, 23(6), 575-589.

Robins, K. y Aksoy, A. (2005). Whoever looks always finds: Transnational viewing and knowledge-experience. En J. Chalaby (ed.), Transnational television worldwide (pp. 14-42). Londres: IB Tauris.

Robins, K. y Aksoy, A. (2006). Thinking experiences. En J. Curran y D. Morley, Media and cultural theory (pp. 86-99). Nueva York: Routledge.

Shandra, J. M. (2007). The world polity and deforestation a quantitative, cross-national analysis. International Journal of Comparative Socio$\log y, 48(1), 5-27$.

Silverstone, R., Hirsch, E. y Morley, D. (1992). Information and communication technologies and the moral economy of the household. En E. Hirsch y R. Silverstone (ed.), Consuming technologies. Londres: Routledge.

Simmons, B., Dobbin, F. y Garrett, G. (2008). The global diffusion of markets and democracy. Cambridge: Cambridge University Press.

Straubhaar, J. D. (1991). Beyond media imperialism: Assymetrical interdependence and cultural proximity. Critical Studies in Media Communication, 8(1), 39-59.

Straubhaar,J. (2003). Choosing national TV: Cultural capital, language, and cultural proximity in Brazil. En M. Elasmar (ed.), The impact of in- 
ternational television (pp. 75-105). Mahwah, New Jersey: Lawrence Erlbaum Associates, Publishers.

Taylor, S. y Bogdan, R. (1987). Introducción a los métodos cualitativos de investigación. Buenos Aires: Paidós.

Thomas, G. (2007). Globalization: The major players. En G. Ritzer (ed.), The blackwell companion to globalization (pp. 84- 102). Oxford: Blackwell Publishing Ltd.

Thussu, D. (2007). Mapping global media flow and contra-flow. En D. Thussu (ed.), Media on the move (pp. 10-29). Abingdon, Oxon: Routledge.

Wilkinson, K. (2003). Language difference in the telenovela trade. Global Media Journal, 2(2), 1-13. 